\title{
Modeling and design of an adaptive control for VSC-HVDC system under parameters uncertainties
}

\author{
Mohamed Amine Kazi, Radouane Majdoul, Nadia Machkour \\ Department of Structural Engineering, Intelligent Systems \& Electrical Energy, University Hassan II Casablanca, \\ Morocco
}

\section{Article Info \\ Article history: \\ Received Mar 28, 2021 \\ Revised Jun 27, 2021 \\ Accepted Jul 19, 2021 \\ Keywords: \\ Adaptive control \\ HVDC-VSC transmission \\ Lyapunov theory \\ Parametric uncertainties}

\begin{abstract}
The growing demand for electricity and the increasing integration of clean energies into the electrical grids requires the multiplication and reinforcement of high-voltage direct current (HVDC) projects throughout the world and demonstrates the interest in this electricity transmission technology. The transmitting system of the voltage source converter-highvoltage direct current (VSC-HVDC) consists primarily of two converter stations that are connected by a dc cable. In this paper, a nonlinear control based on the backstepping approach is proposed to improve the dynamic performance of a VSC-HVDC transmission system, these transport systems are characterized by different complexities such as parametric uncertainties, coupled state variables, neglected dynamics, presents a very interesting research topic. Our contribution through adaptive control based on the backstepping approach allows regulating the direct current (DC) bus voltage and the active and reactive powers of the converter stations. Finally, the validity of the proposed control has been verified under various operating conditions by simulation in the MATLAB/Simulink environment.
\end{abstract}

This is an open access article under the CC BY-SA license.

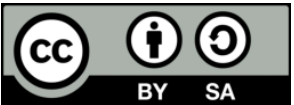

\section{Corresponding Author:}

Mohamed Amine Kazi

Department of Structural Engineering, Intelligent Systems \& Electrical Energy

ENSAM Hassan 2 University

115 Nil Street, Sidi Othmane Casablanca, Morocco

Email: medaminekazi@gmail.com

\section{INTRODUCTION}

Electrical energy is nowadays produced, transmitted, and distributed in alternating current via highvoltage alternating current (AC) transmission networks [1], [2]. This technology is supported by specialists in the field of power electronics because of the simplicity of production and the possibility of changing the level of voltages with the help of transformers. However, the transmission of electrical energy in alternating current faces serious problems that are increasingly difficult to solve [3], especially when the need for electricity is large enough and over long distances, as well as the problem of compensation of reactive power that must be made as close as possible to its consumption in order to limit losses and voltage drops, and the problem of asynchronous links or interconnections [4].

The control of HVDC systems is a vast field open to any research contribution. Many researches have been conducted in order to implement advanced and robust techniques to stabilize and guarantee better performances [5], either by classical proportional-integral (PI) controls [6] or by non-linear controls [7]-[9]. Recent work has focused on topics related to HVDC systems for example the integration of renewable energies in HVDC networks [10], the study and synchronization of converter stations [11], the technology of cables used for HVDC [12], [13], the ripple of capacitor voltages [14]. 
Adaptive control, although old, has been of great interest and has contributed to solving many stabilization and robustness problems for HVDC transport systems [15], work has also dealt with adaptive control based on a reference model reference adaptive control (MRAC) [16]-[18] which has demonstrated the effectiveness of this type of control especially when one wishes to improve the dynamic response and take into account the parametric variations of the system. In this work, we realized an adaptive control based on the backstepping approach of this VSC-HVDC system which allows regulating the direct current (DC) voltage also the active and reactive powers under faults conditions [19]-[21]. The first part will be dedicated to the mathematical modeling of the VSC-HVDC transmission system then the control laws elaborated for the two stations and finally a simulation to test the validity of the control. Figure 1 shows our VSC-HVDC system composed of 2 VSC converters connected to the AC network through an impedance line. On the DC side, the two converter stations are interconnected by DC transmission cables.

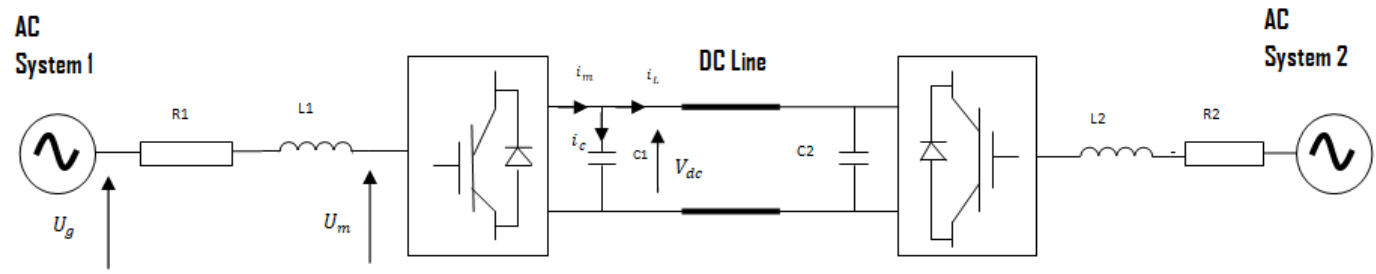

Figure 1. VSC-HVDC system

\section{MODELING OF VSC-HVDC SYSTEM}

Converters are the main actors in an HVDC transmission since they ensure the transformation of the AC power into DC power, as well as the reverse operation. The basic structure of the VSC converter is depicted in Figure 2.

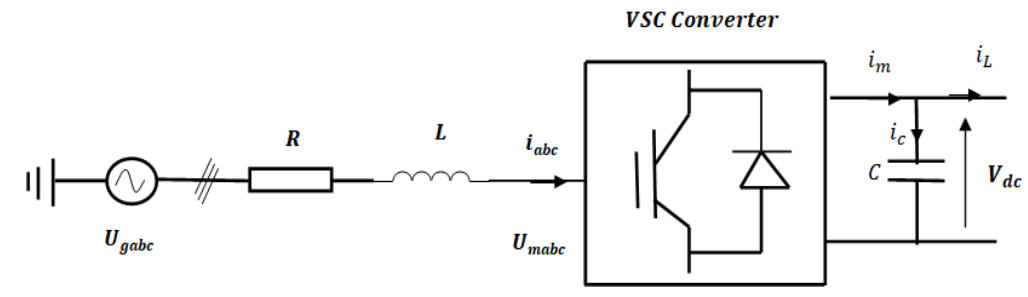

Figure 2. Structure of VSC converter

Applying Kirchhoff's voltage and current laws we find:

$$
L \cdot \frac{d i_{j}}{d t}+R \cdot i_{j}=u_{g j}-u_{m j}
$$

The system (1) can be written as:

$$
u_{m a b c}=-R \cdot i_{a b c}-L \cdot \frac{d i_{a b c}}{d t}+u_{g a b c}
$$

In (2) is then written in the Park transform:

$$
u_{m d q 0}=-R \cdot i_{d q 0}-L \cdot P(\theta) \cdot \frac{d i_{a b c}}{d t}+u_{g d q 0}
$$

The transformation losses being neglected on the converter side, the active power transmitted on the AC side will be the same on the DC side, so we find:

$$
\mathrm{P}_{\mathrm{gdq}}=\mathrm{P}_{\mathrm{DC}}
$$


The active and reactive powers delivered by the source are defined respectively by (5), (6):

$$
\begin{aligned}
& P_{g d q}=\frac{3}{2} \cdot\left(u_{g d} \cdot i_{d}+u_{g q} \cdot i_{q}\right)=\frac{3}{2} \cdot\left(u_{g q} \cdot i_{q}\right) \\
& Q_{g d q}=\frac{3}{2} \cdot\left(u_{g q} \cdot i_{d}-u_{g d} \cdot i_{q}\right)=\frac{3}{2} \cdot\left(u_{g q} \cdot i_{d}\right)
\end{aligned}
$$

If we apply the Kirchhoff current law, it comes:

$$
\begin{aligned}
& \mathrm{i}_{\mathrm{m}}=\mathrm{i}_{\mathrm{c}}+\mathrm{i}_{\mathrm{L}} \\
& \frac{3}{2} \cdot \mathrm{u}_{\mathrm{gq}} \cdot \mathrm{i}_{\mathrm{q}}=\mathrm{V}_{\mathrm{dc}} \cdot\left(\mathrm{i}_{\mathrm{c}}+\mathrm{i}_{\mathrm{L}}\right)
\end{aligned}
$$

Where:

$$
\mathrm{i}_{\mathrm{c}}=\frac{3}{2} \cdot \frac{\mathrm{u}_{\mathrm{q}} \cdot \mathrm{i}_{\mathrm{q}}}{\mathrm{V}_{\mathrm{dc}}}-\mathrm{i}_{\mathrm{L}}
$$

Knowing that

$$
i_{c}=C \cdot \frac{d V_{d c}}{d t}
$$

Thus, the (11) represent represent a first model expressed in the state space as:

$$
\begin{aligned}
& \left\{\begin{array}{c}
\frac{d V_{d c}}{d t}=\frac{3 \cdot u_{g q} \cdot i_{q}}{2 \cdot C \cdot V_{d c}}-\frac{i_{L}}{c} \\
\frac{d i_{q}}{d t}=-\omega \cdot i_{d}-\frac{R}{L} \cdot i_{q}+u_{q} \\
\frac{d i_{d}}{d t}=\omega \cdot i_{q}-\frac{R}{L} \cdot i_{d}+u_{d}
\end{array}\right. \\
& {\left[\begin{array}{lll}
x_{1} & x_{2} & x_{3}
\end{array}\right]^{T}=\left[\begin{array}{lll}
V_{d c} & i_{q} & i_{d}
\end{array}\right]^{T}}
\end{aligned}
$$

Where

$$
\mathrm{u}_{\mathrm{q}}=\frac{\left(\mathrm{u}_{\mathrm{gq}}-\mathrm{u}_{\mathrm{mq}}\right)}{\mathrm{L}} ; \mathrm{u}_{\mathrm{d}}=\frac{\left(\mathrm{u}_{\mathrm{gd}}-\mathrm{u}_{\mathrm{md}}\right)}{\mathrm{L}}
$$

- $\quad i_{d}$ and $i_{q}$ are the current in Park transform.

- $\mathrm{u}_{\mathrm{gd}}, \mathrm{u}_{\mathrm{gq}}$ and $\mathrm{u}_{\mathrm{md}}, \mathrm{u}_{\mathrm{mq}}$ are the dq components of the AC voltage, and VSC converter output voltage respectively.

We set q-axis to be in phase of the source voltage $u_{g}\left(u_{g d}=0\right)$.

\section{NONLINEAR CONTROL OF VSC-HVDC}

\subsection{Introduction}

The control of HVDC systems [22]-[24] requires the development of advanced and robust controls [25] capable of maintaining and guaranteeing high performance in the face of any disturbance or different operating conditions, bearing in mind that an HVDC transport system is considered to be highly non-linear and recognized by its multiple complexities. Adaptive control is a control for non-linear systems [26], [27] using a set of concepts and techniques for the automatic, real-time adjustment of controllers to achieve or maintain a certain level of desired performance when system parameters are unknown or varying, therefore in this paper changes in system parameters will be taken into account and will be formulated in the control laws. The adaptive control will be established is being as station 1 is chosen as a rectifier to regulate the DC bus voltage and reactive power $\mathrm{Q} 1$, station 2 as an inverter to regulate the active power $\mathrm{P} 2$ and reactive power Q2.

\subsection{Control design for the rectifier station}

The mathematical model adopted from (11) is defined: 


$$
\left\{\begin{array}{c}
\dot{x_{1}}=a \cdot \frac{x_{2}}{x_{1}}+D \\
\dot{x}_{2}=-b \cdot x_{2}-\omega \cdot x_{3}+u_{q 1}+\theta_{q 1} \\
\dot{x_{3}}=\omega \cdot x_{2}-b \cdot x_{3}+u_{d 1}+\theta_{d 1}
\end{array}\right.
$$

Where:

$$
\mathrm{a}=\frac{3 \cdot \mathrm{u}_{\mathrm{gq}}}{2 \cdot \mathrm{C}} \mathrm{b}=\frac{\mathrm{R}}{\mathrm{L}} \mathrm{D}=-\frac{\mathrm{i}_{\mathrm{L}}}{\mathrm{c}}
$$

$\theta \mathrm{q} 1$ and $\theta \mathrm{d} 1$ allow to reflect the impedance variation of the AC line, these values must be constant and bounded. The rectifier station is considered of third order and can be controlled by two control inputs. First, the tracking error is defined by:

$$
\mathrm{Z}_{1}=\mathrm{x}_{1 \mathrm{ref}}-\mathrm{x}_{1}
$$

And

$$
\mathrm{Z}_{2}=\gamma-\mathrm{x}_{2}
$$

$\gamma$ is a virtual control law to stabilize $Z_{1}$ The time derivative of $Z_{1}$ and $Z_{2}$ are given:

$$
\dot{\mathrm{Z}}_{1}=\mathrm{x}_{1 \mathrm{ref}}-\mathrm{a} \cdot \frac{\mathrm{x}_{2}}{\mathrm{x}_{1}}-\mathrm{D}
$$

We use the following Lyapunov candidate function:

$$
\mathrm{V}_{0}=\frac{1}{2} \cdot \mathrm{C} \cdot \mathrm{Z}_{1}^{2}
$$

The term $\frac{1}{2}$.C. $Z_{1}^{2}$ represents a capacitor energy fluctuation. The time derivative of $V_{0}$ is given:

$$
\dot{\mathrm{V}}_{0}=\mathrm{C} \cdot \mathrm{Z}_{1}\left(\mathrm{x}_{1 \mathrm{ref}}-\mathrm{a} \cdot \frac{\gamma}{\mathrm{x}_{1}}-\mathrm{D}\right)+\mathrm{a} \cdot \mathrm{C} \cdot \frac{\mathrm{z}_{1} \cdot \mathrm{Z}_{2}}{\mathrm{x}_{1}}
$$

Then if $Z_{2}=0$, we obtain:

$$
\dot{\mathrm{V}}_{0}=-\mathrm{K}_{1} \cdot \mathrm{C} \cdot \mathrm{Z}_{1}^{2}
$$

With:

$$
\gamma=\frac{x_{1}}{a} \cdot\left(x_{1 \text { ref }}-D+K_{1} \cdot Z_{1}\right)
$$

The error $Z_{3}$ is defined as:

$$
\mathrm{Z}_{3}=\mathrm{x}_{3 \mathrm{ref}^{-}} \mathrm{x}_{3}
$$

We derive the two terms $Z_{2}, Z_{3}$ :

$$
\begin{aligned}
& \dot{\mathrm{Z}}_{2}=\dot{\gamma}+\mathrm{b} \cdot \mathrm{x}_{2}+\omega \cdot \mathrm{x}_{3}-\mathrm{u}_{\mathrm{q} 1}-\theta_{\mathrm{q} 1} \\
& \dot{\mathrm{Z}}_{3}=\dot{\mathrm{x}}_{3 \mathrm{ref}}-\omega \cdot \mathrm{x}_{2}+\mathrm{b} \cdot \mathrm{x}_{3}-\mathrm{u}_{\mathrm{d} 1}-\theta_{\mathrm{d} 1}
\end{aligned}
$$

Where:

$$
\dot{\gamma}=\frac{\dot{x_{1}}}{a} \cdot\left(x_{1 \mathrm{ref}}-D+K_{1} \cdot Z_{1}\right)+\frac{x_{1}}{a} \cdot\left(x_{1 \text { ref }}-\dot{D}+K_{1} \cdot \dot{Z}_{1}\right)
$$

The lyapunov function described below is chosen to ensure the asymptotic stability of the system:

$$
\mathrm{V}_{1}=\mathrm{V}_{0}+\frac{1}{2} \cdot \mathrm{L}\left(\mathrm{Z}_{2}^{2}+\mathrm{Z}_{3}^{2}\right)+\frac{1}{2 \cdot \mathrm{m}_{1}} \cdot\left(\widehat{\theta_{\mathrm{q} 1}}-\theta_{\mathrm{q} 1}\right)^{2}+\frac{1}{2 \cdot \mathrm{m}_{2}} \cdot\left(\widehat{\theta_{\mathrm{d} 1}}-\theta_{\mathrm{d} 1}\right)^{2}
$$


Where:

- $\widehat{\theta_{\mathrm{q} 1}}$ and $\widehat{\theta_{\mathrm{d} 1}}$ are the estimates of $\theta_{\mathrm{q} 1}$ and $\theta_{\mathrm{d} 1}$.

- $\mathrm{m}_{1}$ and $\mathrm{m}_{2}$ are the adaptation gains.

- $\frac{1}{2} \cdot \mathrm{L}\left(\mathrm{Z}_{2}{ }^{2}+\mathrm{Z}_{3}{ }^{2}\right)$ represents a capacitor energy fluctuation of the $\mathrm{AC}$ reactor.

Therefore, we get the time derivative of $\mathrm{V}_{1}$ :

$$
\begin{aligned}
& \dot{\mathrm{V}}_{1}=-\mathrm{K}_{1} \cdot \mathrm{C} \cdot \mathrm{Z}_{1}^{2}+\mathrm{L} \cdot \mathrm{Z}_{2}\left(\mathrm{a} \cdot \mathrm{C} \cdot \frac{\mathrm{z}_{1 \cdot}}{\mathrm{L} \cdot \mathrm{x}_{1}}+\dot{\gamma}+\mathrm{b} \cdot \mathrm{x}_{2}+\omega \cdot \mathrm{x}_{3}-\mathrm{u}_{\mathrm{q} 1}-\widehat{\theta_{\mathrm{q} 1}}\right)+ \\
& \mathrm{L} \cdot \mathrm{Z}_{3}\left(\mathrm{x}_{3 \mathrm{ref}}-\omega \cdot \mathrm{x}_{2}+\mathrm{b} \cdot \mathrm{x}_{3}-\mathrm{u}_{\mathrm{d} 1}-\widehat{\theta_{\mathrm{d} 1}}\right)+\left(\widehat{\theta_{\mathrm{q} 1}}-\theta_{\mathrm{q} 1}\right) \cdot\left(\frac{\dot{\theta_{\mathrm{q} 1}}}{\mathrm{~m}_{1}}+\mathrm{L} \cdot \mathrm{Z}_{2}\right)+\left(\widehat{\theta_{\mathrm{d} 1}}-\theta_{\mathrm{d} 1}\right)\left(\frac{\dot{\theta_{\mathrm{q} 1}}}{\mathrm{~m}_{2}}+\mathrm{L} \cdot \mathrm{Z}_{3}\right)
\end{aligned}
$$

In (26) and (27) allow canceling and eliminate the terms $\left(\widehat{\theta_{\mathrm{q} 1}}-\theta_{\mathrm{q} 1}\right)$ and $\left(\widehat{\theta_{\mathrm{d} 1}}-\theta_{\mathrm{d} 1}\right)$ :

$$
\begin{aligned}
& \dot{\overrightarrow{\theta_{\mathrm{q} 1}}}=-\mathrm{m}_{1} \cdot \mathrm{L} \cdot \mathrm{Z}_{2} \\
& \dot{\overrightarrow{\theta_{\mathrm{d} 1}}}=-\mathrm{m}_{2} \cdot \mathrm{L} \cdot \mathrm{Z}_{3}
\end{aligned}
$$

So, we can deduce the two control inputs for the converter (station 1):

$$
\begin{aligned}
& u_{q 1}=a \cdot C \cdot \frac{z_{1}}{L \cdot x_{1}}+\dot{\gamma}+b \cdot x_{2}+\omega \cdot x_{3}-\widehat{\theta_{q} 1}+K_{2} \cdot z_{2} \\
& u_{d 1}=x_{3 r e f}-\omega \cdot x_{2}+b \cdot x_{3}-\widehat{\theta_{d} 1}+K_{3} \cdot z_{3}
\end{aligned}
$$

Then we obtain:

$$
\dot{\mathrm{V}}_{1}=-\mathrm{K}_{1} \cdot \mathrm{C} \cdot \mathrm{Z}_{1}{ }^{2}-\mathrm{K}_{2} \cdot \mathrm{L} \cdot \mathrm{Z}_{2}{ }^{2}-\mathrm{K}_{3} \cdot \mathrm{L} \cdot \mathrm{Z}_{3}{ }^{2} \leq 0
$$

Where $\mathrm{K}_{1}>0, \mathrm{~K}_{2}>0$ and $\mathrm{K}_{3}>0$.

Figure 3 shows control bloc diagram for rectifier station.

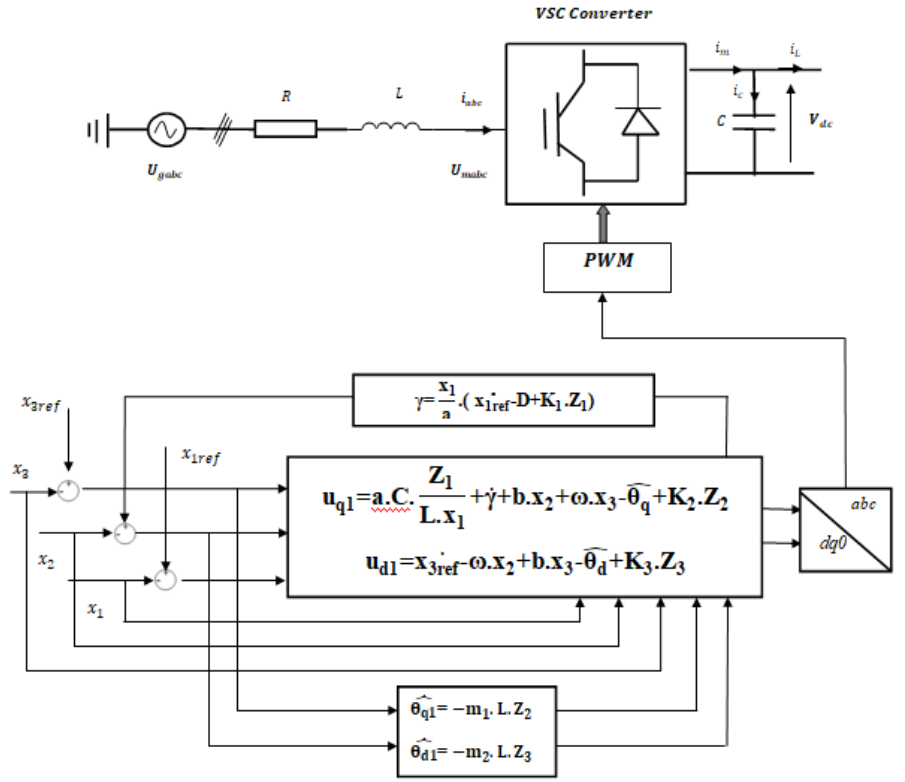

Figure 3. Control bloc diagram for rectifier station 


\subsection{Control design for the inverter station}

This control aims to regulate the active and reactive powers. The state-space of the station operating on power control mode is written is being as:

$$
\left\{\begin{array}{l}
\dot{x_{3}}=-b \cdot x_{4}-\omega \cdot x_{5}+u_{q 2}+\theta_{q 2} \\
\dot{x_{4}}=\omega \cdot x_{4}-b \cdot x_{5}+u_{d 2}+\theta_{d 2}
\end{array}\right.
$$

$\Theta \mathrm{q} 2$ and $\theta \mathrm{d} 2$ allow to reflect the impedance variation of the $\mathrm{AC}$ line, these values must be constant and bounded. The inverter station is considered second-order and can be controlled by two control inputs. First, the tracking error is defined by:

$$
\begin{aligned}
& Z_{4}=x_{4 r e f}-x_{4} \\
& Z_{5}=x_{5 r e f^{-}} x_{5}
\end{aligned}
$$

If we consider the time derivative $Z_{4}$ and $Z_{5}$ :

$$
\begin{aligned}
& \dot{\mathrm{Z}}_{4}=\dot{\mathrm{x}}_{4 \mathrm{ref}}-\omega \cdot \mathrm{x}_{5}+\mathrm{b} \cdot \mathrm{x}_{4}-\mathrm{u}_{\mathrm{q} 2}-\theta_{\mathrm{q} 2} \\
& \dot{\mathrm{Z}}_{5}=\dot{\mathrm{x}}_{5 \mathrm{ref}}-\omega \cdot \mathrm{x}_{4}+\mathrm{b} \cdot \mathrm{x}_{5}-\mathrm{u}_{\mathrm{d} 2}-\theta_{\mathrm{d} 2}
\end{aligned}
$$

To investigate the stability of the errors, a Lyapunov function $\mathrm{V}_{2}$ is chosen as:

$\mathrm{V}_{2}=\frac{1}{2} \cdot \mathrm{L}\left(\mathrm{Z}_{4}{ }^{2}+\mathrm{Z}_{5}^{2}\right)+\frac{1}{2 \cdot \mathrm{m}_{4}} \cdot\left(\widehat{\theta_{\mathrm{q} 2}}-\theta_{\mathrm{q} 2}\right)^{2}+\frac{1}{2 \cdot \mathrm{m}_{5}} \cdot\left(\widehat{\theta_{\mathrm{d} 2}}-\theta_{\mathrm{d} 2}\right)^{2}$

Where:

- $\widehat{\theta_{\mathrm{q} 2}}$ and $\widehat{\theta_{\mathrm{d} 2}}$ are the estimates of $\theta_{\mathrm{q} 2}$ and $\theta_{\mathrm{d} 2}$.

- $\mathrm{m}_{4}$ and $\mathrm{m}_{5}$ are the adaptation gains.

- $\frac{1}{2} \cdot \mathrm{L}\left(\mathrm{Z}_{4}{ }^{2}+\mathrm{Z}_{5}{ }^{2}\right)$ represent a capacitor energy fluctuation of the AC reactor.

The derivative of $\mathrm{V}_{2}$ along the trajectories of the errors is given by:

$$
\dot{\mathrm{V}}_{2}=\mathrm{L} \cdot \mathrm{Z}_{4}\left(\mathrm{x}_{4 \mathrm{ref}}+\omega \cdot \mathrm{x}_{5}+\mathrm{b} \cdot \mathrm{x}_{4}-\mathrm{u}_{\mathrm{q} 2}-\widehat{\theta_{\mathrm{q} 2}}\right)+\mathrm{L} \cdot \mathrm{Z}_{5}\left(\mathrm{x}_{5 \mathrm{ref}}-\omega \cdot \mathrm{x}_{4}+\mathrm{b} \cdot \mathrm{x}_{5}-\mathrm{u}_{\mathrm{d} 2}-\widehat{\theta_{\mathrm{d} 2}}\right)+\left(\widehat{\theta_{\mathrm{q} 2}}-\theta_{\mathrm{q} 2}\right) \cdot\left(\frac{\dot{\theta_{\mathrm{q} 2}}}{\mathrm{~m}_{4}}+\mathrm{L} \cdot \mathrm{Z}_{4}\right)+\left(\widehat{\theta_{\mathrm{d} 2}}-\theta_{\mathrm{d} 2}\right)\left(\frac{\dot{\hat{\mathrm{q}}_{2}}}{\mathrm{~m}_{5}}+\mathrm{L} \cdot \mathrm{Z}_{5}\right)(37)
$$

In (38) and (39) allow canceling and eliminate the terms $\left(\widehat{\theta_{\mathrm{q} 2}}-\theta_{\mathrm{q} 2}\right)$ and $\left(\widehat{\theta_{\mathrm{d} 2}}-\theta_{\mathrm{d} 2}\right)$ :

$$
\begin{aligned}
& \dot{\theta_{\mathrm{q} 2}}=-\mathrm{m}_{4} \cdot \mathrm{L} \cdot \mathrm{Z}_{4} \\
& \dot{\theta_{\mathrm{d} 2}}=-\mathrm{m}_{5} \cdot \mathrm{L} \cdot \mathrm{Z}_{5}
\end{aligned}
$$

So finally, we find the two control inputs on the inverter side (station 2)

$$
\begin{aligned}
& u_{\mathrm{q} 2}=\mathrm{x}_{4 \mathrm{ref}}+\mathrm{b} \cdot \mathrm{x}_{4}+\omega \cdot \mathrm{x}_{5}-\widehat{\theta_{\mathrm{q} 2}}+\mathrm{K}_{4} \cdot \mathrm{z}_{4} \\
& \mathrm{u}_{\mathrm{d} 2}=\mathrm{x}_{5 \mathrm{ref}} \cdot \omega \cdot \mathrm{x}_{4}+b \cdot \mathrm{x}_{5}-\widehat{\theta_{\mathrm{d} 2}}+\mathrm{K}_{5} \cdot \mathrm{z}_{5}
\end{aligned}
$$

Where $\mathrm{K}_{4}>0$ and $\mathrm{K}_{5}>0$

Thus, we arrive at the stabilization equation

$$
\dot{\mathrm{V}}_{2}=-\mathrm{K}_{4} \cdot \mathrm{L} \cdot \mathrm{Z}_{4}{ }^{2}-\mathrm{K}_{5} \cdot \mathrm{L} \cdot \mathrm{Z}_{5}{ }^{2} \leq 0
$$

The Barbalat and LaSalle-Yoshizawa theorems [27] confirm the convergence of tracking errors to zero $\sum_{\mathrm{i}=1}^{5} \mathrm{Z}_{\mathrm{i}} \rightarrow 0$. Figure 4 shows control bloc diagram for rectifier station. 


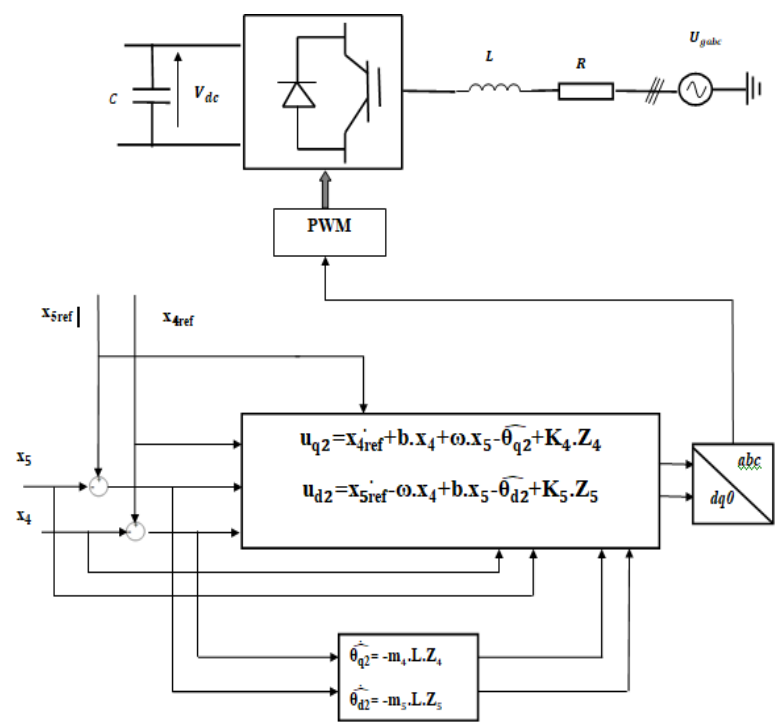

Figure 4. Control bloc diagram for inverter station

\section{SIMULATION ANALYSIS AND RESULTS}

In order to test the efficiency of the proposed control and the system behavior under different operating conditions, a simulation is carried out under the MATLAB/Simulink environment. Figure 5 shows the studied system. Table 1 presents the simulation parameters of the studied system:

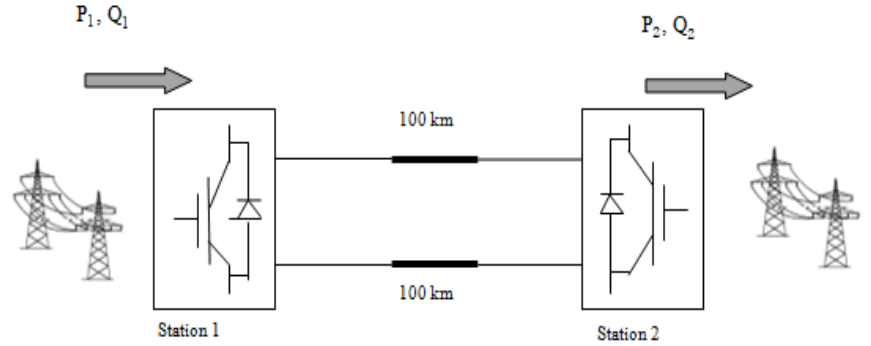

Figure 5. VSC-HVDC transmission system
Table 1. Simulation parameters

\begin{tabular}{cc}
\hline Parameters of the study system & Value \\
\hline Each AC System nominal voltage & $320 \mathrm{KV}$ \\
Each DC nominal voltage & $250 \mathrm{KV}$ \\
Base power & $1000 \mathrm{MVA}$ \\
Resistor R1 and R2 & $900 \mathrm{~m} \Omega$ \\
Inductance L1 and L2 & $16.5 \mathrm{mH}$ \\
DC Link capacitor C & $80 \mu \mathrm{F}$ \\
Nominal frequency & $50 \mathrm{~Hz}$ \\
Length of transmission line & $100 \mathrm{Km}$ \\
DC cable resistance & $13,9 \mathrm{~m} \Omega / \mathrm{km}$ \\
DC cable inductance & $0,159 \mathrm{mH} / \mathrm{km}$ \\
DC cable capacitance & $0,231 \mu \mathrm{F} / \mathrm{km}$ \\
\hline
\end{tabular}

In order to carry out a simulation study and test the validity of the proposed control, we have proposed the following action points, Case $1: \mathrm{t}<2 \mathrm{~s}$ normal operating condition. $\mathrm{t}=2 \mathrm{~s}$ a line break occurs at phase 2 and causes an imbalance on the AC network of station 1, Figure 6 shows this behavior. Figure 7 shows the response of the DC bus for both stations, it can be seen that the system follows the setpoint despite the phase break produced at $\mathrm{t}=2 \mathrm{~s}$ and converges quickly to the reference value.

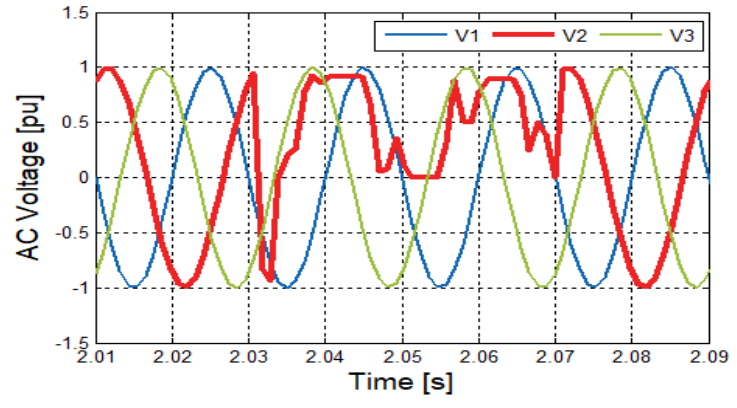

Figure 6. Single-phase fault at station 1

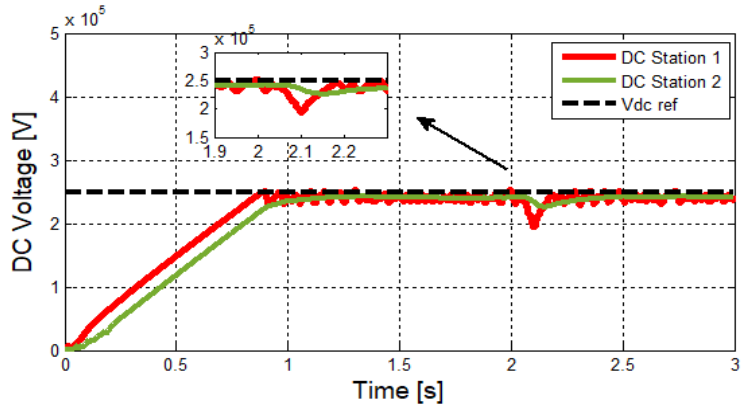

Figure 7. DC-link voltage 
Case 2: A common problem in electrical power systems is voltage dips, which are defined as a sudden drop of $10 \%$ or more of the nominal voltage, affecting one or more phases, lasting between eight milliseconds, and one minute. Generally, voltage dips are considered as disturbances, and therefore, to test the robustness of our system, we have caused this phenomenon during the period between $1.5 \mathrm{~s}$ and $2 \mathrm{~s}$ as shown in Figure 8. Figure 9 and Figure 10 show the behavior of the DC bus for the two stations in the presence of the voltage dip phenomenon, it is clear that there is a stabilization of the voltages and a convergence towards the reference value $V_{\text {dcref }}=250 \mathrm{KV}$.

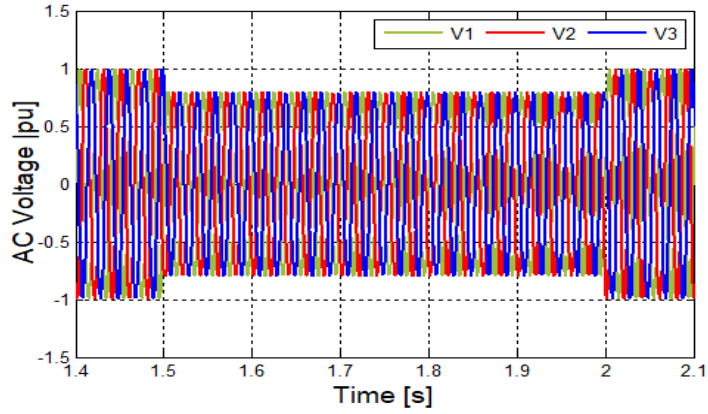

Figure 8. Grid voltage in station 1

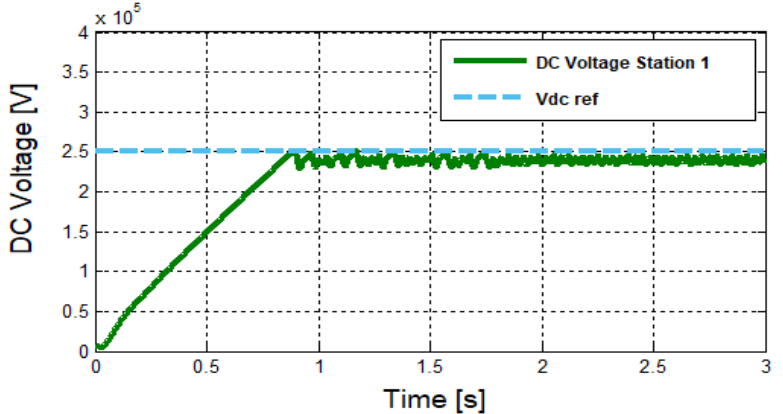

Figure 9. DC voltage station 1

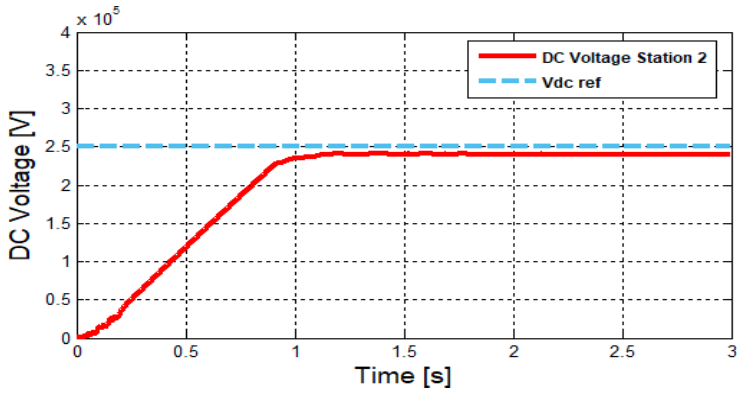

Figure 10. DC voltage station 2

Figure 11 and Figure 12 show the evolution of the active and reactive powers of each station knowing that the imposed reference inputs are $\mathrm{Q}_{1 \mathrm{ref}}=0.3 \mathrm{pu}$ and $\mathrm{P}_{2}=-0.5 \mathrm{pu}$. It is clear from the simulation results presented that the proposed control strategy can stabilize the system by attenuating fluctuations in the DC bus voltages, dampen the oscillations of the controlled variables, and ensure the regulation of active and reactive power. The faults injected in the HVDC system, which are respectively the phase break and the voltage dip, allowed to test the robustness of the adaptive control.

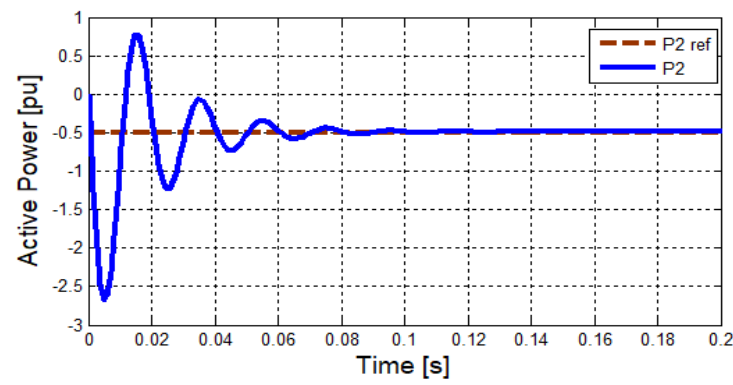

Figure 11. Active power station 2

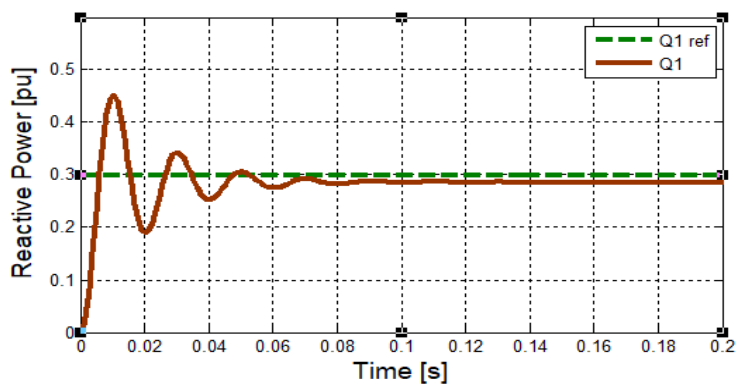

Figure 12. Reactive power Station 1

The proposed control offers a smoother control compared with the results of the sliding mode control [28], [29], especially the oscillation or chattering problems inherent to this type of discontinuous 
control that appears quickly. Note that chattering can excite neglected high-frequency dynamics sometimes leading to instability. The integration of the parameters $\theta \mathrm{q}$ and $\theta \mathrm{d}$ allows to quickly catch up with the setpoint during line break failures compared to a normal backstepping control [30-32].

After multiple tests of different values for adaptation gains, it was found that taking very small or much higher values than those taken in Table 2 instantly causes divergence and instability in the system therefore the values of design adaptation gains of the elaborated adaptive control have a major impact on the final control, so the choice of these parameters is very important, despite the difficulty of obtaining optimal values. This paper does not provide the means to select these parameters properly. Table 2 shows the values chosen for each station.

Table 2. Controller parameters

\begin{tabular}{lll}
\hline & Station 1 & Station 2 \\
\hline & $\mathrm{K}_{1}=10^{3}$ & \\
Backstepping controller & $\mathrm{K}_{2}=11600$ & $\mathrm{~K}_{4}=300$ \\
parameters \& adaptation gains & $\mathrm{K}_{3}=1710$ & $\mathrm{~K}_{5}=254$ \\
& $\mathrm{~m}_{1}=150$ & $\mathrm{~m}_{4}=200$ \\
& $\mathrm{~m}_{2}=210$ & $\mathrm{~m}_{5}=150$ \\
\hline
\end{tabular}

\section{CONCLUSION}

This paper deals with the subject of the control of a VSC-HVDC system, we proposed the control of two converter stations connected to each other via a DC network. We proposed an adaptive control based on the backstepping method which allows taking into account the variations of the system parameters and improves its dynamic behavior. Through the simulation results obtained, we note that the control strategy adopted leads to a significant improvement of the system performance compared to a classical PI control and also to a better control of the active and reactive powers of the stations despite the presence of disturbances, even of some defects that may appear due to the complexity of the power transmission system and the unmeasurable random disturbances that may arise at any time, and not forgetting the difficulty of finding optimal values for adaptation gains. As a perspective our attention will be directed to the study of MTDC multi-terminal HVDC transport systems with integration of renewable energies and also, to study the MMC modular multi-level converters which are widely used in electric energy transport applications.

\section{REFERENCES}

[1] A. Abuzayed, "An overview of HVDC applications: a study on medium voltage distribution networks," thesis for: Bachelor of Science in Energy Engineering, December 2017, doi: 10.13140/RG.2.2.13790.95048.

[2] J. Dorn, H. Gambach, and D. Retzmann, "HVDC transmission technology for sustainable power supply," International Multi-Conference on Systems, Signals \& Devices, 2012, pp. 1-6, doi: 10.1109/SSD.2012.6198109.

[3] C. R. Bayliss, C. Bayliss, and B. Hardy, "Transmission and distribution electrical engineering," Elsevier, 2012.

[4] K. Meah, and S. Ula, "Comparative evaluation of HVDC and HVAC transmission systems," 2007 IEEE Power Engineering Society General Meeting, 2007, pp. 1-5, doi: 10.1109/PES.2007.385993.

[5] S. Ruihua, Z. Chao, L. Ruomei, and Z Xiaoxin, "VSCs based HVDC and its control strategy," 2005 IEEE/PES Transmission \& Distribution Conference \& Exposition: Asia and Pacific, 2005, pp. 1-6, doi: 10.1109/TDC.2005.1546800.

[6] F. Yang, Z. Xu, and J. Zhang, "An approach to select PI parameters of HVDC controllers," 2006 IEEE Power Engineering Society General Meeting, 2006, p. 5, doi: 10.1109/PES.2006.1709261.

[7] X. Y. Li, "A nonlinear emergency control strategy for HVDC transmission systems," Electric Power Systems Research, vol. 67, no. 3, pp. 153-159, December 2003, doi: 10.1016/S0378-7796(03)00086-5.

[8] L. Xu, B. R. Andersen, and P. Cartwright, "Control of VSC transmission systems under unbalanced network conditions," 2003 IEEE PES Transmission and Distribution Conference and Exposition (IEEE Cat. No.03CH37495), 2003, pp. 626-632 vol.2, doi: 10.1109/TDC.2003.1335349.

[9] S.-Y. Ruan, G.-J. Li, X.-H. Jiao, Y.-Z. Sun, and T. T. Lie, "Adaptive control design for vsc-hvdc systems based on backstepping method," Electric Power Systems Research, vol. 77, no. 5-6, pp. 559-565, April 2007, doi: 10.1016/j.epsr.2006.05.006.

[10] Y. Li, et al., "Study on AC-side dynamic braking-based fault ride-through control for islanded renewable energy system with grid-connected VSC-HVDC transmission," 2017 Chinese Automation Congress (CAC), 2017, pp. 6108-6111, doi: 10.1109/CAC.2017.8243877.

[11] G. Macchia, M. Trovato, M. Dicorato, and G. Forte, "Modelling of VSC-HVDC with power synchronization method including frequency support," 2019 AEIT HVDC International Conference (AEIT HVDC), 2019, pp. 1-6, doi: 10.1109/AEIT-HVDC.2019.8740551.

[12] G. Lagrotteria, D. Pietribiasi, and M. Marelli, "HVDC Cables-The technology boost," 2019 AEIT HVDC 
International Conference (AEIT HVDC), 2019, pp. 1-5, doi: 10.1109/AEIT-HVDC.2019.8740645.

[13] U. Vercellotti, "HVDC links at increased voltage, CESI experience on extruded cable systems up to 525kV," 2019 AEIT HVDC International Conference (AEIT HVDC), 2019, pp. 1-5, doi: 10.1109/AEIT-HVDC.2019.8740439.

[14] M. Marchesoni, M. Passalacqua, L. Vaccaro, M. Carpita, S. Gavin, and S. Kissling, "Capacitor voltage ripple minimization in voltage source converter for HVDC applications," 2019 AEIT HVDC International Conference (AEIT HVDC), 2019, pp. 1-6, doi: 10.1109/AEIT-HVDC.2019.8740647.

[15] J. Reeve, and M. Sultan, "Robust adaptive control of HVDC systems," in IEEE Transactions on Power Delivery, vol. 9, no. 3, pp. 1487-1493, July 1994, doi: 10.1109/61.311220.

[16] M. E. Abdallah, O. M. Arafa, A. Shaltot, and G. A. Abdel-Aziz, "MRAC-based vector oriented control of a Wind turbine-driven DFIG," 2016 Eighteenth International Middle East Power Systems Conference (MEPCON), 2016, pp. 597-603, doi: 10.1109/MEPCON.2016.7836953.

[17] M. Doumi, I. Colak, A. G. Aissaoui, M. Abid, and A. Tahour, "Robust MRAC for a wind turbine based on a doubly-fed induction generator," 2017 IEEE 6th International Conference on Renewable Energy Research and Applications (ICRERA), 2017, pp. 1160-1165, doi: 10.1109/ICRERA.2017.8191236.

[18] N. Golea, A. Golea, and M. Kadjoudj, "Robust MRAC adaptive control of PMSM drive under general parameters uncertainties," 2006 IEEE International Conference on Industrial Technology, 2006, pp. 1533-1537, doi: 10.1109/ICIT.2006.372420.

[19] J. Yang, J. E. Fletcher, and J. O'Reilly, "Short-circuit and ground fault analyses and location in VSC-based DC network cables," in IEEE Transactions on Industrial Electronics, vol. 59, no. 10, pp. 3827-3837, Oct. 2012, doi: 10.1109/TIE.2011.2162712.

[20] J. Wang, M. Huang, C. Fu, H. Li, S. Xu, and X. Li, "A new recovery strategy of HVDC system during AC faults," in IEEE Transactions on Power Delivery, vol. 34, no. 2, pp. 486-495, April 2019, doi: 10.1109/TPWRD.2019.2892410.

[21] A. Li, Z. Cai, Q. Sun, X. Li, D. Ren, and Z. Yang, "Study on the dynamic performance characteristics of HVDC control and protections for the HVDC line fault," 2009 IEEE Power \& Energy Society General Meeting, 2009, pp. 1-5, doi: 10.1109/PES.2009.5275974.

[22] S. Tale, M. Mohan, and K. P. Vittal, "Performance analysis of distance relay in an AC grid with VSC-HVDC connection," 2017 International Conference on Intelligent Computing, Instrumentation and Control Technologies (ICICICT), 2017, pp. 1363-1368, doi: 10.1109/ICICICT1.2017.8342768.

[23] J. O. Bernat and R. Preece, "Impact of VSC-HVDC reactive power control schemes on voltage stability," 2019 IEEE Milan PowerTech, 2019, pp. 1-6, doi: 10.1109/PTC.2019.8810794.

[24] N. F. Ibrahim and S. S. Dessouky, "VSC-HVDC control system," Design and Implementation of Voltage Source Converters in HVDC Systems, Springer, Cham, 2021, pp. 15-30, doi: 10.1007/978-3-030-51661-1_3.

[25] M. Ayari, M. M. Belhaouane, X. Guillaud, and N. B. Braiek, "Nonlinear control design of VSC-MTDC systems based on Backstepping approach," 2015 12th International Conference on Informatics in Control, Automation and Robotics (ICINCO), 2015, pp. 596-602.

[26] B. Pal and B. Chaudhuri, "Linear Control in power systems," Robust Control in Power Systems, 2005, pp. 13-38, doi: 10.1007/0-387-25950-3_3.

[27] T. I. Fossen, "Handbook of marine craft hydrodynamics and motion control, Appendix A: Nonlinear Stability Theory, John Wiley \& Sons, 2011.

[28] B. PrasannaLakshmi, K. Ramesh, and R. Kiranmayi, "HVDC transmission system of sliding mode controller Vis-aVis Pi controller," in International Journal for Research in Applied Science \& Engineering Technology (IJRASET), vol. 6, no. 1, pp. 2941-2953, January 2018, doi: 10.22214/ijraset.2018.1404.

[29] B. Saber, B. Abselkader, B. Mansour, and B. Said, "sliding mode control of three levels back-to-back VSC-HVDC system using space vector modulation," in International Journal of Power Electronics and Drive System (IJPEDS), vol. 4, no. 2, pp. 265-273, June 2014.

[30] S. Bouafia, A. Benaissa, M. Bouzidi, and S. Barkat, "Backstepping control of three-levels VSC based back-to-back HVDC system," 3rd International Conference on Systems and Control, 2013, pp. 900-905, doi: 10.1109/ICoSC.2013.6750964.

[31] P. H. Divshali, G. B. Gharehpetian, and S. H. Hosseinian, "VSC-HVDC controller parameter tuning base on optimization," in Iranian Conference on Electrical Engineering, January 2011.

[32] R. Majdoul, E. Abdelmounim, M. Aboulfatah, and A. Abouloifa, "The Performance comparative of backstepping, sliding mode and PID controllers designed for a single-phase inverter UPS," 2014 International Conference on Multimedia Computing and Systems (ICMCS), 2014, pp. 1584-1589, doi: 10.1109/ICMCS.2014.6911310. 